\title{
Assessment, Selection and Demonstration of Technologies and Equipment for Measuring Welder Exposure to Ozone during GMAW (MIG Welding) on Aluminum Alloys
}

\author{
Thomas Neil McManus ${ }^{1,2} \&$ Assed N. Haddad ${ }^{3}$ \\ ${ }^{1}$ NorthWest Occupational Health \& Safety, North Vancouver, Canada \\ 2 Programa de Engenharia Ambiental, Universidade Federal do Rio de Janeiro, Rio de Janeiro, Brazil \\ ${ }^{3}$ Programa de Engenharia Ambiental, Universidade Federal do Rio de Janeiro, Rio de Janeiro, Brazil \\ Correspondence: Thomas Neil McManus, NorthWest Occupational Health \& Safety, North Vancouver, BC., \\ V7K1P3, Canada. E-mail: nwohs@mdica
}

Received: December 8, 2019

Accepted: January 2, $2020 \quad$ Online Published: January 15, 2020

doi:10.5539/enrr.v10n1p14

URL: https://doi.org/10.5539/enrr.v10n1p14

\begin{abstract}
Ozone is a by-product of arc welding on aluminum alloys and stainless steels. Assessment of exposure is difficult because emissions are short in duration and large in magnitude compared to background levels, and generally occur unpredictably during work activity. The welding environment is particularly harsh. This study applied a systematic process to identify technologies and sampling devices available in the marketplace and to select suitable candidates and reject unsuitable ones. Candidates suitable for study included colorimetric detector tubes, an Ultra-Violet (UV) air pollution analyzer, and person-portable instruments, one containing a heated semi-conductor sensor and the other an electrochemical sensor. These devices were exposed to welding plumes contained in a pre-conditioned plastic bag and to unconfined plumes during production welding (Gas Metal Arc Welding [GMAW] commonly known as Metal Inert Gas [MIG welding]) on aluminum alloys. Nitrogen dioxide is an interferent in the assessment of ozone exposure by almost all technologies. Particulates and unreacted metal atoms in the plume further complicate measurement of ozone. None of the measurement technologies overwhelmed the others in this application. The harshness of the welding environment eliminated several candidates. Colorimetric detector tubes provided the best compromise between performance and safety in proof-of-concept testing on welders.
\end{abstract}

Keywords: aluminum alloys, argon shielding, GMAW (MIG welding), measurement technologies, method development, proof-of-concept testing, sampling equipment, systematic process

\section{Introduction}

\subsection{Ozone Production and Arc Welding on Aluminum Alloys}

Ozone $\left(\mathrm{O}_{3}\right)$, triatomic oxygen, forms during interaction between oxygen molecules and energy sources capable of inducing the reaction. One of the most important sources of energy for production of ozone is ultra-violet (UV) energy at wavelengths less than $250 \mathrm{~nm}$ (McKinley, 1992). Arc welding and cutting processes emit UV energy at these wavelengths. Gas Metal Arc Welding (GMAW) also known as Metal Inert Gas (MIG) welding using argon shielding is a major source of UV emission and by extension, ozone production (NIOSH, 1998). Gas Tungsten Arc Welding (GTAW) also known as Tungsten Inert Gas (TIG) welding emits considerably less UV than GMAW (MIG welding). Ozone generation is possible at any point in space reached by UV emissions containing wavelengths less than $250 \mathrm{~nm}$ (1). Ozone produced off-axis can expose welders not actively welding and other workers performing tasks unrelated to welding (McManus \& Haddad, 2013).

Ozone is chemically aggressive and attacks materials and living tissue. (Lenntech, 2019). The primary targets in the body are the mucus membranes in the eyes, nose and the respiratory system (ACGIH, 2001). The current TLV-TWA (Threshold Limit Value - Time-Weighted Average) reflects level of exertion. The current values are $0.10 \mathrm{ppm}$ during light exercise; $0.08 \mathrm{ppm}$ during moderate exercise; and $0.05 \mathrm{ppm}$ during heavy exercise averaged over 8 hours (ACGIH, 2018). Many regulatory authorities starting with WorkSafeBC, the regulator in British Columbia, Canada where this study occurred use TLVs as regulatory Exposure Limits and require 
employers to determine exposure of workers to evaluate compliance by comparison against these values (WorkSafeBC, 2019).

This article is one of a series on assessment of exposure to contaminants produced during argon-shielded arc welding on aluminum alloys (McManus \& Haddad, 2013; McManus \& Haddad, 2014; McManus \& Haddad, 2015a; McManus \& Haddad, 2015b; McManus \& Haddad, 2016; McManus \& Haddad, 2018; McManus \& Haddad, 2019a; McManus \& Haddad, 2019b). Other articles in the series determined exposure to UV and blue hazard visible emissions (McManus \& Haddad, 2013); use of methanol as a coolant during machining (McManus \& Haddad, 2014); oxygen level during welding (McManus \& Haddad, 2015a); possible role of argon in abnormal fatigue (McManus \& Haddad, 2015b; Cr(VI) emissions (McManus \& Haddad, 2016); exposure of welders to ozone (McManus \& Haddad, 2019a); and selection and application of technology and sampling devices for measuring exposure of welders to $\mathrm{NO} / \mathrm{NO}_{2}$ (nitric oxide and nitrogen dioxide) (McManus \& Haddad, 2018; McManus \& Haddad, 2019b).

\subsection{Purpose for this Study}

This study had two main objectives. The first was to identify and evaluate technologies and sampling devices available in the marketplace for measuring welder exposure to ozone and then to select the most appropriate one. The second objective was to demonstrate use of the technology and sampling device under actual conditions of exposure in order to confirm applicability and to create a defensible and repeatable procedure for use in a broad study.

Discussion of the process of selection rarely occurs in the literature or in training courses. Hence, there is little guidance for analyzing the problem to identify factors needing consideration in selection of the technology and sampling device, and development of the method. The marketplace offers a number of different technologies of measurement implemented in sampling devices. While making a selection from promotional material is relatively facile, this approach offers no guarantee of success when used in the welding environment. Concepts described here are applicable in other areas where this analysis must occur. The critical requirement for achieving success is a systematic approach.

\subsection{Challenges of Exposure Assessment during Arc Welding}

Exposure to emissions from arc welding is difficult to evaluate. The environment is extremely hostile; emissions are brief, and occurrence is unpredictable. Arc welding creates an environment hostile to people and equipment. Arc welding is unusual because of the necessary proximity of the worker to very hazardous conditions and the almost total reliance on personal protective equipment to prevent injury and possible death. The reality of the manner in which arc welding occurs creates the welding environment and the challenges imposed on welders and the technologies available for assessing exposure to ozone in air. There is considerable incentive, therefore, to identify the technology most capable of surviving in the welding environment and assessing exposure in the manner as free from bias as possible due to interference from other substances.

The marketplace offers several technologies and sampling devices for measuring ozone. The strategy used to select the most appropriate technology and sampling device builds on discussion of several concerns: demands imposed by requirements essential to provide welder safety; demands of the welding environment on the sampling device; and demands of the signal on the detection technology. Table 1 and subsequent discussion expand on these themes. These provide the basis for first-level comparison against the strengths and limitations intrinsic in the technologies and sampling devices.

Assessment of personal exposure requires positioning the sensitive element of the measurement device in the 'breathing zone' (Lynch, 1994). Capability to position the sensitive element in this area depends on design of the sampling device, size, capability to resist damage caused by the arc and molten metal, and capability to attach the device to welding protective clothing and equipment. Welder safety overrides protection of the sampling device against damage and destruction. Hence, the sensitive part of the device must be small and not interfere with the position of the welding helmet and other personal protective equipment required during welding in order to satisfy this requirement.

Rise of the plume above the arc and interaction with the breathing zone depend on posture and orientation of the welder relative to the location of the arc (McManus \& Haddad, 2018; McManus \& Haddad, 2019a). In some orientations, the plume passes up the upper torso and the welding helmet. The welding helmet influences exposure of the face to the plume (Goller \& Paik, 1985). During welding, the manner in which protection is provided by the closed welding helmet during passage of the plume through the breathing zone is not intuitively obvious. Hence, full closure of the welding helmet during sampling for ozone is essential for welder safety. 
Table 1. Elements in the Strategy for Selecting Technology and a Sampling Device for Assessing Welder Exposure to Ozone

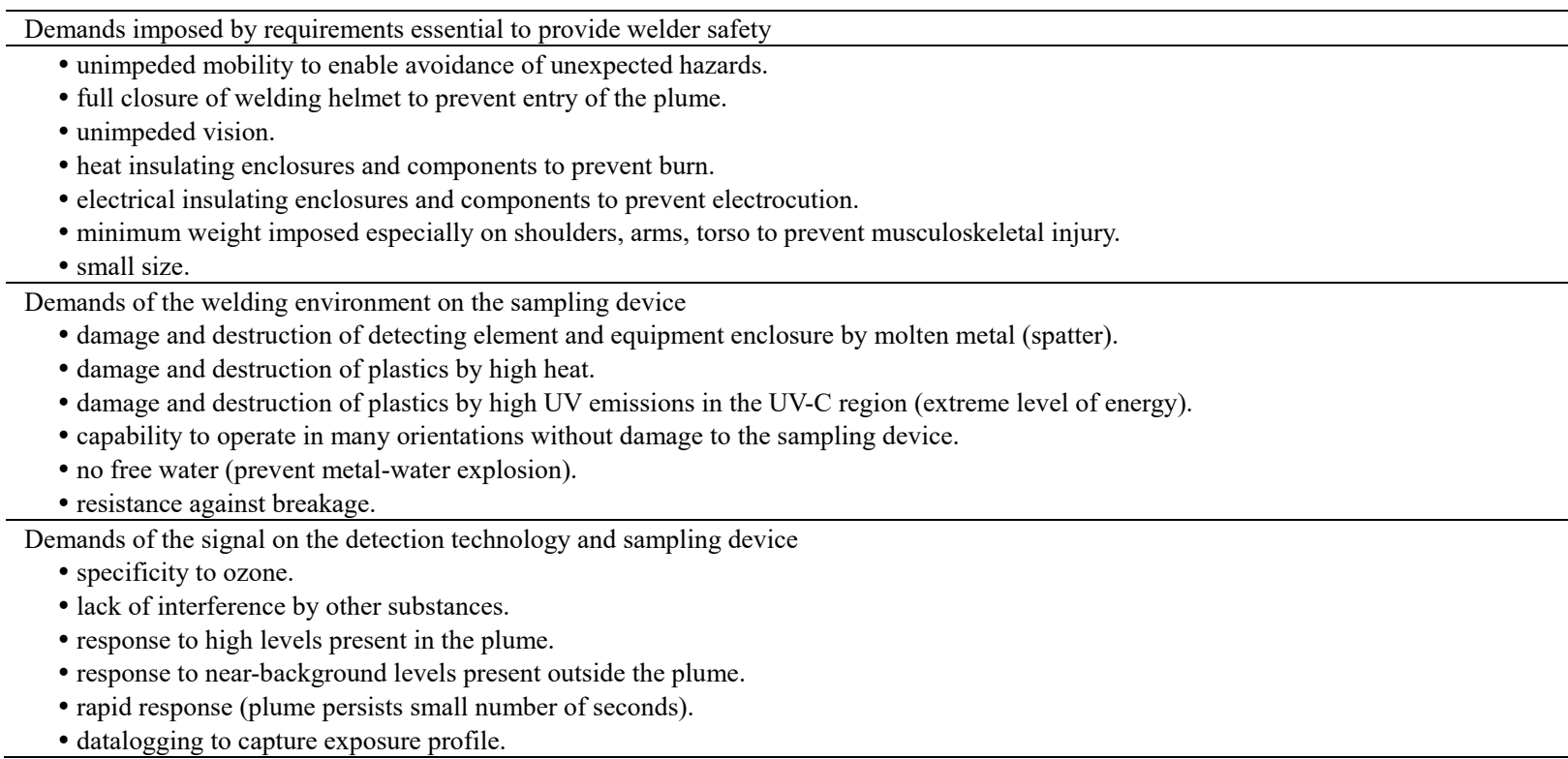

The sampling device must not readily conduct heat as this could lead to a hot point source having potential to cause a burn injury following contact with unprotected skin. In addition, the presence of flowable water in the device poses a serious safety concern. The combination of water with molten aluminum creates an explosible condition.

Some sampling devices require tethering (connection of the sensitive element to a device positioned remote to the welder). Tethering can impede or prevent mobility. Welders must have unhindered mobility in order to enable rapid movement away from a perceived or real hazardous condition. Unhindered mobility may be achievable while tethering is occurring but requires prior planning to ensure successful implementation of the strategy.

The mode of exposure to ozone is another consideration in the selection of a measurement technology. Exposure during welding is short-term and occurs during bursts often lasting only seconds at a time. Effectively, exposure to the welding plume is modelled as an OFF-ON-OFF signal. Duration of the ON portion during which exposure to ozone present in the plume can occur depends on the equipment, manual or robotic, employed during welding. The sampling technology must respond rapidly from ambient level to the level of ozone produced during welding and be able to respond rapidly to decrease in the level. The sampling technology also must respond to low levels of ozone.

Interferences are a major concern during measurement of exposure to ozone. Ozone reacts with NO (nitric oxide) and many other substances. NO forms on hot surfaces during contact between oxygen and nitrogen. NO reacts with oxygen and ozone to produce $\mathrm{NO}_{2}$ (Seinfeld \& Pandis, 1998). This reaction diminishes the level of ozone, while increasing the level of $\mathrm{NO}_{2}$. Some formulations of shield gas contain a small amount of $\mathrm{NO}$ in order to exploit the reaction to form $\mathrm{NO}_{2}$ thereby to minimize the level of ozone (Moyer, 2019). Nitrogen dioxide also is chemically reactive and reacts similarly with many of the same substances as ozone. This situation can render unsuitable technologies where the detection process responds to both ozone and $\mathrm{NO}_{2}$ because of the possibility of overestimation of the true concentration of ozone.

Experience has shown that the presence or absence of airborne particulates influence the production and distribution of ozone. When the air is clean, other workers can receive off-axis exposure from UV emitting into the surrounding space (McKinley, 1992; McManus, 2013). Exposure from ozone contained in the plume disappears rapidly after extinguishment of the arc due to continued rise to the highest level in the structure and removal by reaction to form $\mathrm{NO}_{2}$ (Moyer, 2019; Thermo Electron, 2004). Exposure to ozone also can occur because of entrapment of the welding plume by surfaces overhead in the structure in which welding is occurring.

A critically important consideration in this discussion is the perspective of the welder. The overriding focus of the welder during argon-shielded arc welding on aluminum alloys is the integrity of the gaseous shield. The 
argon shield is created by controlled emission of gas from the tip of the welding gun. The shield surrounds the arc in a geometry created by the metal to be joined together, the torso of the welder, and the tip of the welding gun. Welders do not tolerate diversion from this focus to necessities imposed by operation of the sampling device. Hence, the choice of technology and its implementation in the sampling device must be compatible with this reality.

An additional possible factor was the work location, a shipyard. Fabrication of structures occurred in a building. The building was partly climate-controlled. Humidity control and cleanliness are important issues in large-scale work involving arc welding on aluminum alloys. As a result, the air was clean compared to conditions present during uncontrolled arc welding on coated carbon steel where 'welding smoke' can fill the airspace in the building.

Based on previous discussion, the ideal measuring technology would have characteristics listed in Table 2. Functionality and survival in the welding environment demand ruggedness, compactness, rapid response, accuracy, and freedom from interference by other air contaminants. The ability of commercially available technologies and sampling equipment to meet these requirements in this application is by no means certain.

Table 2. Characteristics Desirable in a Device for Measuring Ozone in an Arc Welding Environment

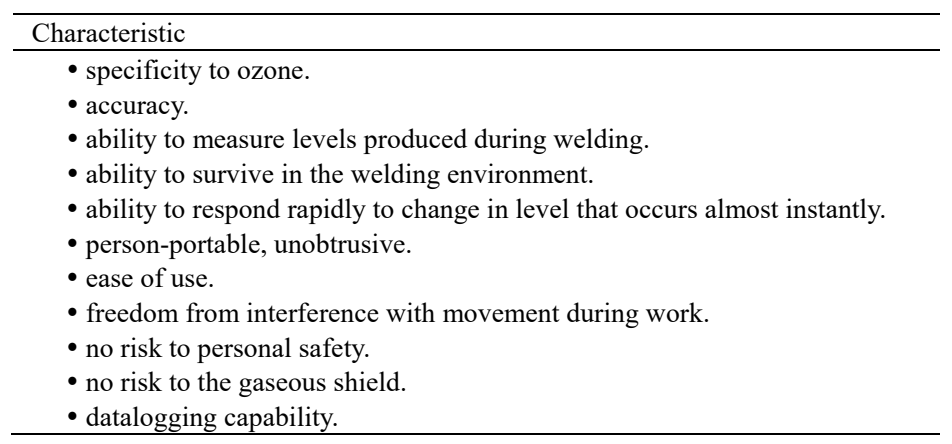

\section{Method}

\subsection{Identification and Selection of Technology and Sampling Devices for Measuring Ozone during Arc Welding}

The focus of the first part of this study was identification of a detection technology capable of performing satisfactorily in the welding environment. The starting-point was comparison of detection technologies as implemented in different products described in literature made available by manufacturers and resources listed on the Internet.

Initial screening provided the basis for rapid exclusion of the iodide-triiodide wet chemical method (OSHA, 2008; Rakness et al., 1996) and the chemiluminescence analyser (Anseros, 2016; TAPI, 2016). Rejection of the former occurred to eliminate the presence of water in the weld area. Rejection of the latter occurred because of tethering combined with use of compressed flammable gases. This left for consideration colorimetric detector tubes (Dräger, 2011; Gastec 2012; Sensidyne, 2006), a UV absorption analyser (TECO, 1994), and two hand-held instruments, one containing a solid-state sensor (Eco Sensors, 2000) and the other, an electrochemical sensor (ENMET, 2002).

The second phase of the first part of the evaluation involved determination of performance of the technologies and sampling devices when subjected to the welding plume. Manufacturers evaluate equipment under static, controlled conditions. Previous discussion has indicated that the welding environment poses difficult measurement challenges. An air pollution analyser while somewhat impractical for routine measurement of worker exposure does provide the basis for simultaneous comparison of performance of the technologies chosen for technical evaluation (air pollution analyser, portable instruments, colorimetric detector tubes) using a common source (a welding plume collected in a sample train preconditioned with ozone.) The intent of this approach was to protect instruments made available for evaluation from potential damage that could occur in the welding environment, and at the same time to enable comparison of capabilities when subjected to the same atmosphere. 


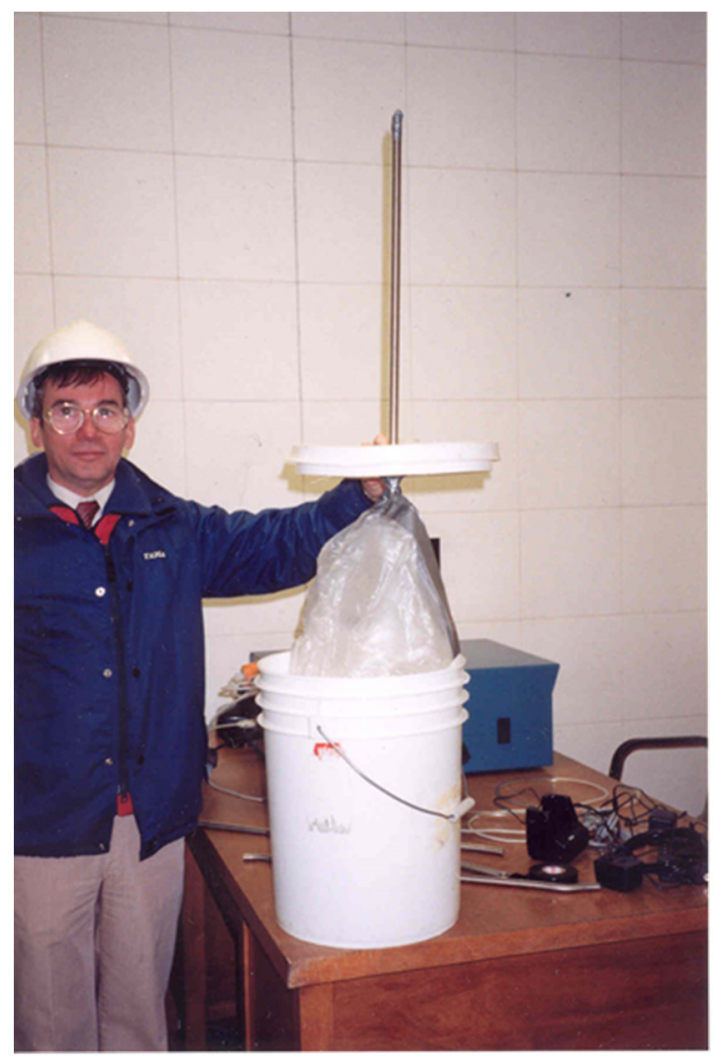

Figure 1. Components of the sampling train. The welding plume flows through the metal tube into the plastic bag when the vacuum cleaner removes the air from inside the pail

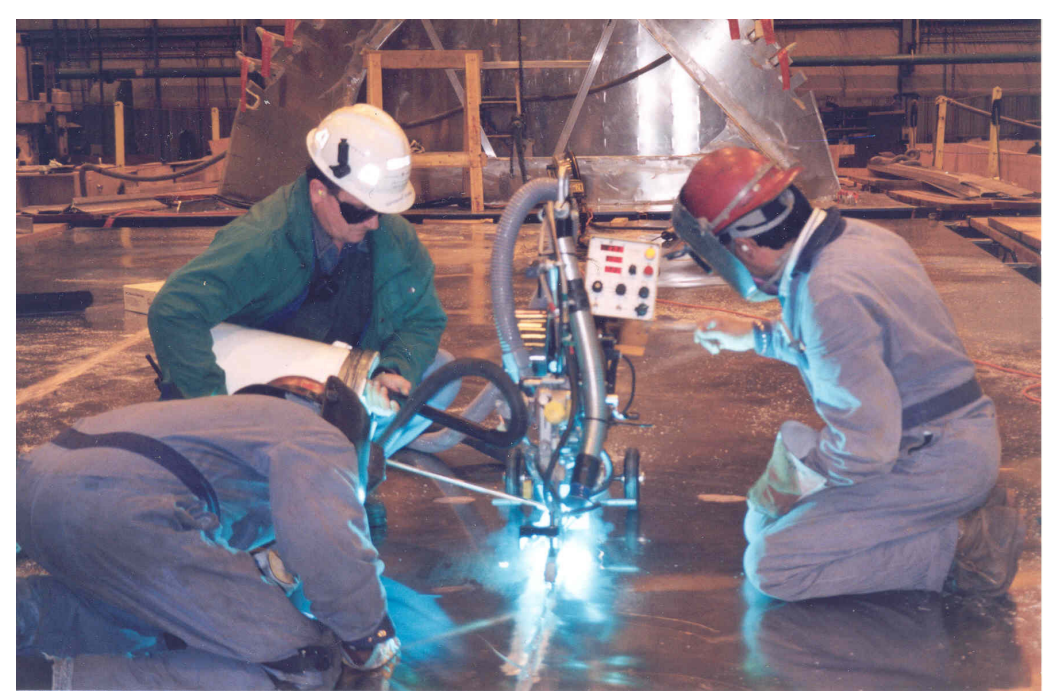

Figure 2. Collecting the welding plume for use in testing instrument response. The black hose connecting to the vacuum cleaner creates a vacuum inside the pail. Note: This photo shows a highly inappropriate practice not to be imitated, namely failure to protect the skin of the face and the hands against exposure to UV emissions from the arc

The apparatus for collecting the plume consisted of a $20 \mathrm{~L}$ plastic pail containing two thin-walled plastic bags of polyethylene, one inside the other. The inner bag was connected to a stainless-steel tube that projected through the lid of the pail (Figure 1). The outer bag acted as a back-up. During sample collection, the welding plume was drawn through the stainless-steel tube into the plastic bag by the vacuum created in the surrounding airspace in 
the sealed pail by a portable vacuum cleaner (Figure 2). The inside surfaces of the plastic bag and the stainless-steel tube were pre-conditioned several times by overnight exposure to welding plumes prior to conducting the tests using the instruments in order to minimize loss of ozone during sample collection due to reaction on interior surfaces. (Loss due to reaction by ozone and other gases on these surfaces posed no consequence to this evaluation.) The inlet to the stainless-steel tube normally was positioned above the shoulder of the welders in the plume that passed by the face. This location provided a means of assessing exposure to the breathing zone.

The portable instruments under test (Eco Sensors, Model A-21ZX, Eco Sensors Division of KWJ Engineering, Newark CA and ENMET SPECTRUM, ENMET Corporation, Ann Arbor, MI) were positioned inside a 4 L polyethylene plastic bag containing the minimum necessary free volume. This bag also contained a tube connected to the intake of the UV ozone analyzer (TECO Model 49, Thermo Environmental Instruments, Inc., Franklin MA) and a connection to the stainless-steel tube of the sample collection apparatus. The sensors of the handheld instruments and the intake to the UV ozone analyzer were positioned equidistant from the end of the tube through which the sample entered. The plastic bag holding the instruments was aged as described previously. All of these instruments have the capability to show conditions in real time on an LCD display. The colorimetric detector tubes did not provide this capability. The reading on scale on the tube was an average that developed over the period of sampling time.

At the start of the assessment, the instruments were activated and provided time to stabilize. Upon delivery of the sample from the Fabrication Building, the stainless-steel tube of the apparatus was connected to the bag containing the instruments. The delay between the end of collection of the plume and the start of measurement after connecting the sample bag to the bag holding the instruments was approximately 30 seconds. The sample was drawn into the bag holding the instruments using a portable sampling pump (SKC Inc., Eighty-Four, PA) operating at $2 \mathrm{~L} / \mathrm{min}$ and the sampling pump in the ozone analyzer operating at $0.6 \mathrm{~L} / \mathrm{min}$ for a total flow-through of $2.6 \mathrm{~L} / \mathrm{min}$. The portable sampling pump drew waste sample from the bag containing the instruments through a large respirator cartridge containing charcoal prior to flow through the pump and discharge to the environment. Adsorption on charcoal was an effective means for removing ozone from waste air discharged into the room where the ozone analyzer was located (Johnston et al., 1989; Thermo Electron, 2004). The sampling train was evacuated and flushed with uncontaminated air in the same manner at the end of each sample run.

Primary welding equipment used on this project was the ESAB SVI 450 CV/CC (ESAB Canada, Mississauga, $\mathrm{ON}$ ) power source with the MIG 4HD ultra pulse wire feeder using a push/pull gun in the pulsed GMAW mode (Swint, 2015). Table 3 provides details of the welding parameters (CSA Group, 2011). The shield gas was argon. Welding on frames (a structure found in the bottom of a vessel) occurred for relatively long duration, upwards of 30 seconds.

Table 3. Welding parameters during sampling for ozone.

\begin{tabular}{|c|c|c|}
\hline Parameter & $\begin{array}{l}\text { Current } \\
\text { Amperes }\end{array}$ & $\begin{array}{l}\text { Voltage } \\
\text { Volts }\end{array}$ \\
\hline \multicolumn{3}{|l|}{ GMAW (MIG welding) } \\
\hline horizontal fillet weld (5083 base material, ER-5183 wire, $1.2 \mathrm{~mm}$ diameter) & 190 to 240 & 24 to 25 \\
\hline vertical up fillet weld (5083 base material, ER-5183 wire, $1.2 \mathrm{~mm}$ diameter) & 160 to 190 & 24 to 25 \\
\hline overhead fillet weld ( 5083 base material, ER-5183 wire, $1.2 \mathrm{~mm}$ diameter) & 180 to 220 & 24 to 25 \\
\hline \multicolumn{3}{|l|}{ Voltage shall not vary more than $\pm 10 \%$. } \\
\hline \multicolumn{3}{|l|}{ Current shall not vary more than $\pm 15 \%$. } \\
\hline \multicolumn{3}{|l|}{ When using 6061 base material, current and voltage are higher. } \\
\hline CSA-CWB W47.2 Aluminum (32) was followed during this work. & & \\
\hline
\end{tabular}

\section{Notes:}

(a) '5083 base material' refers to the type of aluminum alloy used in the structure.

(b) 'ER-5183 wire' refers to the aluminum alloy in the sacrificial wire utilized in the welding process.

(c) 'GMAW (MIG welding)' means Gas Metal Arc Welding (Metal Inert Gas welding).

(d) 'CSA-CWB W47.2 Aluminum' refers to Canadian Standards Association - Canadian Welding Bureau consensus standard W47.2 Aluminum which describes requirements for consistency during welding on aluminum alloys (CSA Group, 2011). 


\subsection{Proof of Concept Testing}

In the second part of the first phase of this study, the instruments were exposed to the welding environment in the Assembly Building order to ascertain performance under actual operating conditions. The sensing element of the device was positioned into the welding plume to determine response to the high concentration of ozone and other air contaminants emitted simultaneously at the arc.

The second part of the study reports on use of the selected technology and sampling device in a limited study in an actual welding environment in order to confirm suitability for evaluation of worker exposure. Sampling on two welders performing production welding (GMAW) occurred using colorimetric detector tubes (Ozone 0.05/b, No. 6733181, Dräger Safety Inc., Pittsburgh, PA; and Ozone Detector Tube, No. 18L, Gastec Corporation, Fukayanaka, Ayase-City, Japan).

Samples were obtained in the breathing zone over the shoulder in the path of the plume after it had passed the face of the welder (Figure 3). A section of flexible plastic tubing about $2 \mathrm{~m}$ in length was used to provide necessary separation between the sample taker and the welder. As needed to obtain the number of pump strokes required by the tube, sampling occurred during several welds. The welders worked at the interface of a vertical and a horizontal surface (1F, 1G, 2F) (ASME, 2010). Sampling using the two products occurred sequentially, rather than in a side-by-side comparison.

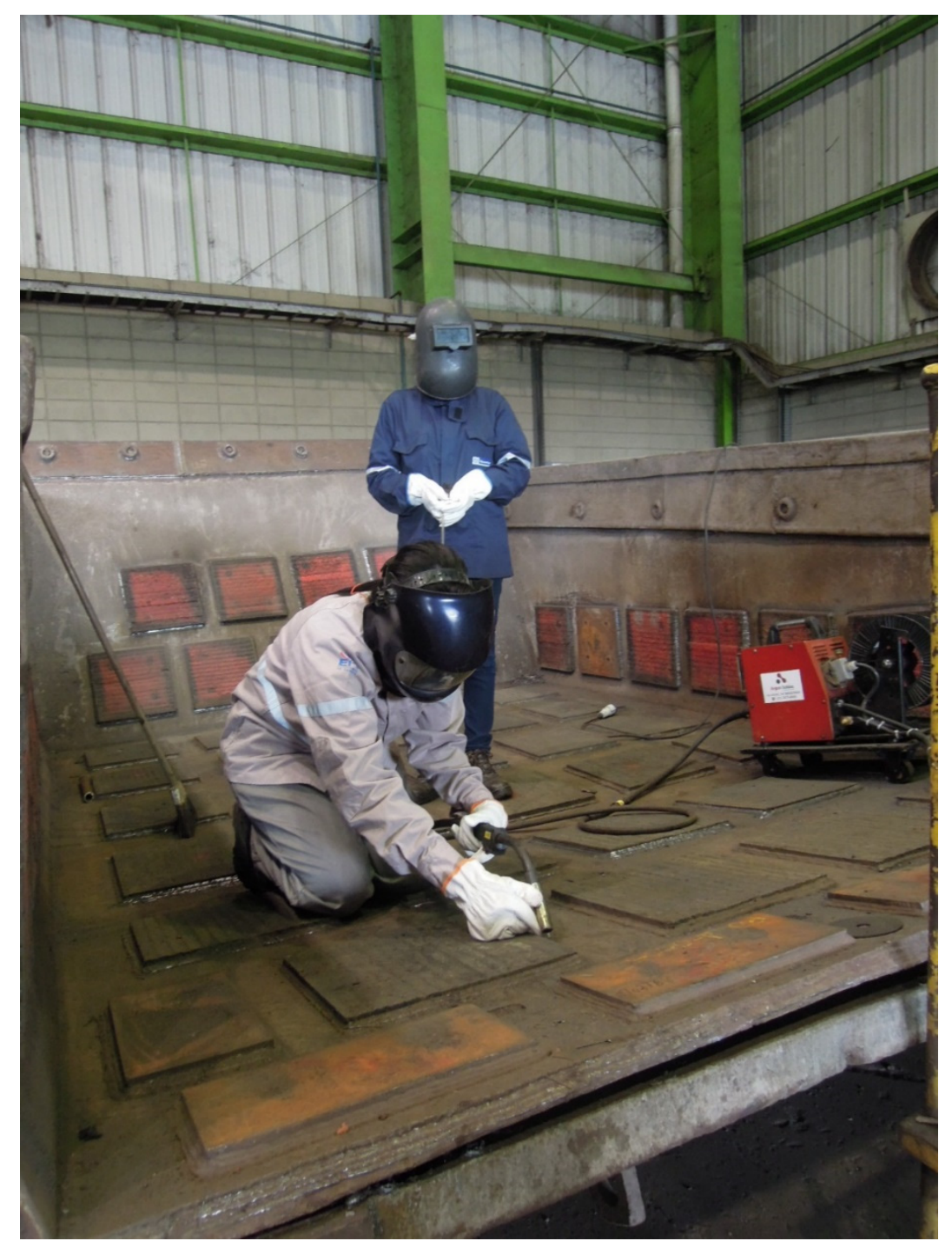

Figure 3. Mock-up showing the welder and the sample-taker. In this test, sampling occurred only during production of the welding plume. Prior testing in the absence of welding confirmed the ability to minimize interference with rapid movement of the welder to avoid hazardous conditions 
Statistical analysis on this data occurred using Industrial Hygiene Data Analyst Lite Edition (IHDataAnalyst-LE) (Exposure Assessment Solutions, Inc., Morgantown, WV, www.oesh.com).

WorkSafeBC, the regulator in British Columbia, requires employers to assess the conditions of work. This assessment required cooperation and active participation from welders and other workers at the shipyard. Everyone who participated was a volunteer and gave informed consent. Prior to the start, each prospective participant received a brief explanation about what the equipment did and what information it created and stored. Anyone uncomfortable with participation was excused, no questions asked, and without repercussion. No names were recorded to ensure that there was no means to identify participants.

\section{Results}

\subsection{Selection of Technology and Sampling Devices}

Table 1 identified demands imposed on sampling devices by welder safety; demands imposed on sampling devices by the welding environment; and demands imposed on the sampling technology. Table 4 identifies strengths, weaknesses and limitations of sampling technologies evaluated for suitability and subsequently during testing.

Table 4. Strengths, Weaknesses and Limitations of Measurement Technologies for Ozone

\begin{tabular}{|c|c|}
\hline Strengths & Weaknesses and Limitations \\
\hline $\begin{array}{l}\text { Colorimetric Detector Tubes } \\
\text { - Inexpensive. } \\
\text { - Reasonable time needed for sample collection per tube. } \\
\text { - Unobtrusive sampling. } \\
\text { - Rapid availability of result. } \\
\text { - Sample collection can match duration of the plume. } \\
\text { - Reading displayed on the scale on the tube during sample collection. } \\
\text { - Semi-permanent record of result. }\end{array}$ & $\begin{array}{l}\text { - Single use, many tubes required. } \\
\text { - Time-weighted average during period of sample } \\
\text { collection. } \\
\text { - Sample taker must maintain the position of the device } \\
\text { and operate the pump during sample collection. } \\
\text { - Most labor intensive, sample taker required. } \\
\text { - No datalogging. } \\
\text { - Interference by NO2 at high level. }\end{array}$ \\
\hline $\begin{array}{l}\text { UV Ozone Analyzer } \\
\text { - Specific to ozone (gas phase only). } \\
\text { - Collection can match duration of the weld. } \\
\text { - Rapid response to change in concentration. } \\
\text { - Rapid return to background level when exposure ceases. } \\
\text { - No memory effect. } \\
\text { - Reading displayed on the instrument during sample collection. } \\
\text { - Datalogging possible. }\end{array}$ & $\begin{array}{l}\text { - Very expensive. } \\
\text { - Large and heavy. } \\
\text { - Requires sample train connecting the instrument to the } \\
\text { worker during sampling. } \\
\text { - Requires } 110 \mathrm{~V} \text { power supply. } \\
\text { - Labor intensive. } \\
\text { - Tethering to the welder during sampling restricts } \\
\text { movement during work. } \\
\text { - Possible interference by airborne particulates. } \\
\text { - Potential contamination of interior surfaces by deposition } \\
\text { of particles. }\end{array}$ \\
\hline $\begin{array}{l}\text { Portable Instrument - Heated Semiconductor Sensor } \\
\text { - Very compact, easily positioned. } \\
\text { - Moderate cost. } \\
\text { - Rapid response to change in concentration. } \\
\text { - Reading displayed on the instrument during sample collection. }\end{array}$ & $\begin{array}{l}\text { - Position ensuring that the sensor experiences exposure to } \\
\text { the plume in the breathing zone possibly obtrusive to the } \\
\text { wearer. } \\
\text { - Interference from air currents, particulates, NO2, other } \\
\text { chemical substances. } \\
\text { - Sensor retains memory of high concentration, long } \\
\text { period of recovery to background level. } \\
\text { - Labor intensive. } \\
\text { - Very sensitive to environmental conditions. } \\
\text { - No datalogging. } \\
\text { - Potential contamination of interior surfaces by deposition } \\
\text { of particles. } \\
\text { - Inability to read the screen during welding. }\end{array}$ \\
\hline $\begin{array}{l}\text { Portable Instrument - Electrochemical Sensor } \\
\text { - Person portable. } \\
\text { - Moderate cost. } \\
\text { - Return to background level when exposure ceases. } \\
\text { - No memory effect. } \\
\text { - Least labor intensive. } \\
\text { - Reading displayed on the instrument. } \\
\text { - Datalogging possible. }\end{array}$ & $\begin{array}{l}\text { - Positioning in the breathing zone invasive to the wearer. } \\
\text { - Very slow response to change in concentration. } \\
\text { - Attainment of maximum displayed value (full response) } \\
\text { requires }>240 \mathrm{~s} \text {. } \\
\text { - Potential contamination of sensor membrane by } \\
\text { deposition of particles. } \\
\text { - Inability to read the screen during welding. }\end{array}$ \\
\hline
\end{tabular}


Table. 5 contains an example of the response of the UV ozone analyzer to contents of the bag sample. The level of ozone reported by the instrument rose within 1 minute to the maximum level and decreased thereafter during removal of the plume from the sample collection bag into the bag containing the instruments. The decrease in concentration during removal of the plume from the sample bag following initial response of the instrument suggested disappearance of some of the ozone in the sample. Loss of ozone in the sample occurred due to reaction between ozone and nitric oxide $(\mathrm{NO})$ in the plume to form nitrogen dioxide $\left(\mathrm{NO}_{2}\right)$ as indicated in previous discussion (Moyer, 2019; Thermo Electron 2004), and possible continuing reaction with the plastic wall of the sample bag and reaction with particulate components in the plume. The end of the sample period corresponded with removal of all of the plume (about $20 \mathrm{~L}$ ) from the sample collection bag located in the plastic pail. While not shown in Table 5, the display of the UV ozone analyzer rapidly returned to background after exposure to room air resumed.

Table 5. Response of the Ozone Analyzer to Contents of the Bag Sample

\begin{tabular}{lll}
\hline Description & $\begin{array}{l}\text { Elapsed Time } \\
(\mathrm{min})\end{array}$ & $\begin{array}{l}\text { Ozone Concentration } \\
(\mathrm{ppm})\end{array}$ \\
\hline Background & Not applicable & 0.0025 (typical value) \\
Filtered air & Not applicable & 0.0010 (typical value) \\
Sample transport to office & 0.5 & \\
Sample run & start pump & 0.0030 \\
& 1 & 0.864 \\
2 & 0.797 \\
3 & 0.629 \\
4 & 0.450 \\
& 5 & 0.385 \\
& 6 & 0.322 \\
& 7 & 0.234 \\
& 8 & 0.198 \\
9 & 0.151 \\
& 10 & 0.122 \\
\hline
\end{tabular}

\section{Notes:}

(a) Background refers to the concentration of ozone in the room measured by the UV ozone analyzer.

(b) Filtered air refers to the concentration of ozone in air filtered through a large respirator cartridge containing activated charcoal prior to entering the UV ozone analyzer.

(c) Sample transport to office refers to the delay estimated between the end of sample collection and introduction of the sample into the bag containing the instruments.

(d) Sample run refers to measurement of ozone in the bag containing the instruments. Measurement began immediately following connection of the sampling tube to the inlet of the bag containing the instruments and continued until removal of the plume from the sample collection bag.

During the initial runs, only the UV ozone analyzer responded to ozone passing through the small bag containing the portable instruments. To test the possibility that the cause of the problem was orientation in the bag or some environmental factor in the office, the handheld instruments were positioned in the plume during welding activity. During this exposure, the level of ozone on the display of the heated semiconductor instrument (Eco Sensors, Model A-21ZX) increased rapidly to above $5 \mathrm{ppm}$ and then decreased rapidly to background when exposure ceased. Concentrations as high as $6.5 \mathrm{ppm}$ were recorded during some of the tests of the heated semiconductor instrument, in side-by-side comparison with readings provided by the UV ozone analyzer. These values considerably exceeded the levels in the typical run reported in Table 5.

This type of response occurred on several occasions. As this instrument lacks datalogging capability, data on the rate of rise and level of response are not available. The accuracy of the values reported here is not known because of the caveat from the manufacturer about use of the instrument in an environment containing high levels of particulates as are present during welding and the presence of $\mathrm{NO}_{2}$, a recognized interferent in the measurement of ozone. Once exposed to a high level of ozone, the heated semiconductor instrument was unable to respond to subsequent challenges without a prolonged recovery lasting several hours. This situation severely limited the applicability of this instrument to the assessment of ozone exposure during arc welding and paralleled 
comments made by the manufacturer about such situations. The inability of this instrument to respond to the ozone challenge when operated in the bag in the office environment was never explained.

The ozone analyzer displayed negative values (at least $-2 \mathrm{ppm}$ ) during some of the tests. These values were unexpected and inconsistent with normal performance by instruments. This observation raised serious concerns about the validity of data generated through this instrument when used in the welding environment. The instrument was loaned for evaluation without a means to remove particulates from the airflow. For any further application in this environment, an inlet filter or other means to remove particulates from the gaseous components in the plume would be essential.

The display of the SPECTRUM instrument (ENMET Corporation) containing the electrochemical sensor increased slowly to $0.18 \mathrm{ppm}$ after about $20 \mathrm{~s}$ of exposure to the plume. The manufacturer indicated that this instrument requires at least $240 \mathrm{~s}$ to reach the full reading (ENMET, 2002). An average pass by a welder lasts usually $30 \mathrm{~s}$ or less. This situation means that this instrument would never be able to reach full response. This limitation severely limited application of this instrument in the welding environment for measurement of ozone.

Testing under actual conditions in the welding environment identified the presence of severe limitations in the technologies and implementation in various sampling devices that on paper otherwise seemed quite serviceable.

\subsection{Proof of Concept Testing}

Table 6 presents results from sampling for ozone in the breathing zone of welders during argon-shielded production welding (GMAW) using colorimetric detector tubes (Dräger, Ozone 0.05b and Gastec 18L, Ozone low range). Results are listed in ascending order of concentration, rather than sequence of measurement.

Table 6. Results from Sampling Using Colorimetric Detector Tubes

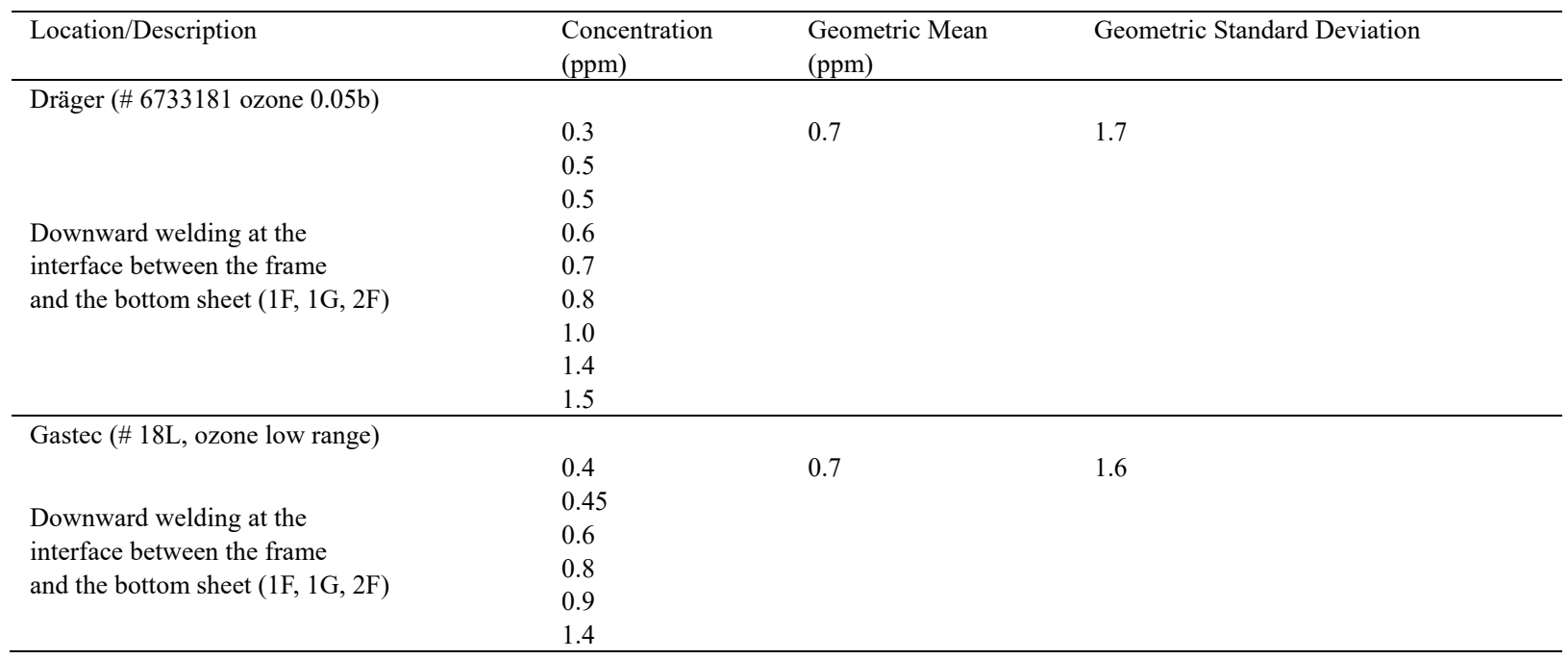

\section{Notes:}

(a) (1F, 1G, 2F) and similar nomenclature refer to welding orientation (ASME, 2010).

(a) readings presented here reflect concentrations obtained during multiple welds performed by production welders in the course of their daily activity. While similar, the conditions and geometries are not identical.

(b) readings obtained with the Dräger tube often occurred during a single weld. Readings obtained with the Gastec tube occurred during several welds.

Concentrations varied widely, ranging from 0.3 to $1.5 \mathrm{ppm}$ for the Dräger product and 0.4 to $1.4 \mathrm{ppm}$ for the Gastec product. The analysis program, IHDA-LE indicated that the samples fit the lognormal distribution and that the distributions for both groups of samples are indistinguishable. This type of distribution is typical in environmental sampling.

Dräger samples require 5 pump strokes. Each pump stroke required about 10 seconds. Gastec samples also require 5 pump strokes. Each pump stroke in this case required at least 30 seconds. Dräger tubes are larger in diameter and produce a more easily read change in color than the Gastec product. The Dräger tube is more amenable to this application, since completion of sampling is more likely to occur prior to cessation of welding. Detector tubes provide a time-weighted average over the duration of the sample. They are not reusable beyond a single sample. 


\section{Discussion}

\subsection{Selection of Technology and Sampling Device}

The first part of this study documented considerations involved in selection of the best available technology to use for measuring exposure in a hazardous industrial environment when several are available. Usually the decision is straight-forward. This is not the case during welding because of the hazardous nature and requirements of this environment. These include the hazards of the process; the need for protection of the worker and the sampling device; the need to position the sensing element of the sampling device in a specific location (the breathing zone); the need for unhindered movement by the worker; the characteristics and demands of the signal to be measured; and the potential for interferences in the measurement.

Each of the technologies examined during this work offered strengths and suffered from weaknesses and limitations (Table 4). Impinger sampling (OSHA, 2008; Rakness et al., 1996) as required in wet chemical methods is very difficult to perform in a real-world environment. Welders assume many postures during this work. Impingers must remain upright in order to prevent spillage. Welding as a physical activity imposes a risk of damage and destruction on this equipment. Wet chemical methods generally require glassware. Glassware is bulky and breaks easily. Durability and protection of this equipment against spillage and breakage during welding and related work therefore are major issues. Spillage of water-based solutions and contact with molten aluminum pose a major risk of explosion and spattering of molten metal. The latter was the primary reason for excluding this technology from further consideration.

Interferences posed an additional concern. Ability of this methodology to respond to brief high-level exposures is not known. Response depends on concentration of ozone and the volume of air sampled. Nitrogen dioxide also reacts with iodide to produce tri-iodide. Reducing dusts, such as finely ground aluminum produced during grinding and aluminum atoms in the plume, captured by the apparatus can react with liberated iodine and thereby produce negative interference with the chemistry. For these additional reasons, this technology was excluded from further consideration.

Air pollution analyzers (Anseros, 2019; TAPI, 2016; TECO, 1994) offer reasonable specificity to ozone but suffer from lack of portability and problems associated with tethering to the worker. Use of extension tubing between the sampling point on the worker and the instrument imposes a delay in analysis of the sample and potential loss of analyte. Determining an estimate of concentration of ozone in the plume during welding would require locating the sampling inlet of the UV ozone analyzer as close as possible to the source rather than in a remote protected location. This requirement severely hampered utility of this instrument owing to its physical size and weight, and the need for a $110 \mathrm{~V}$ electrical supply. This configuration in addition would pose risk of injury to the welder who must have free movement without constraint during this work. Operation of chemiluminescence units requires a cylinder of compressed ethylene or NO. For this reason and because of the additional concern about the potential for fire involving the cylinder containing ethylene, the chemiluminescence analyzer was eliminated from further consideration for use in routine monitoring of worker exposure to ozone. Ozone-specific instruments provide the basis for comparing the response of other measurement technologies. In this case, the UV ozone analyzer would be the best choice because of greater specificity.

The portable instrument containing the heated semiconductor sensor (Eco Sensors, 2000) offered many positive features when compared to requirements stated in Table 1 and comments in Table 3. This instrument, however, suffers from a number of serious limitations mentioned in documentation provided by the manufacturer. This instrument is susceptible to turbulence associated with air currents. This information indicates that the inlet of the instrument should be oriented perpendicular to or face away from air flows in order to avoid readings that are abnormally high. These requirements for operation would be impossible to achieve during use of the instrument as a personal dosimeter by an individual in a welding environment. The manufacturer also recommends against operating the instrument in environments containing large quantities of aerosols, acid gases, and chlorine and sulphur compounds. The welding plume contains considerable quantities of particulate aerosols. The fan in the instrument would be unable to draw air through a filter employed to remove aerosols from the airstream. Particulates in welding plumes possibly could impair the function of the sensor. Nitrogen dioxide is an acknowledged interferent in the measurement of ozone using this technology.

The portable instrument containing the electrochemical sensor (ENMET, 2002) offers another option for measuring ozone. The instrument is wearable. Attachment in the breathing zone of the entire instrument is necessary in order to position the sensitive element in this area. Such attachment requires special consideration because of concern about worker safety and potential destruction of the sensing element of the instrument. Information from the manufacturer indicated that at least 240 seconds of exposure were needed to achieve full 
response. This means that full response to rapid change in the signal could not occur.

Colorimetric detector tubes (Dräger, 2011; Gastec, 2012; Sensidyne, 2006) offer a long history of service in many environments. Comments in Table 1 and Table 2 indicate that these products deserved further consideration. Colorimetric detector tubes seem to offer the greatest number of advantages and the least number of weaknesses and limitations listed in Table 4. This formed the basis for selection of this technology for use in measuring welder exposure to ozone contained in the welding plume. The detector tube (the sensing element) is easily and unobtrusively positioned in the breathing zone.

Colorimetric detector tubes function on the principle that the substance of interest contained in air drawn through the tube by a pump reacts with a chemical substance immobilized in the packing that changes color. The length of change in color in the substance immobilized in the tube corresponds to a scale calibrated in concentration units (ppm). The packing in the tube that stabilizes and contains the chemically reactive material also prevents contact with potentially reactive airborne particulate matter including aluminum dust and aluminum atoms. The most desirable operational characteristics for assessing exposure to ozone during welding are a small number of pump strokes of short duration along with a color change and scale that are easily read.

Ozone reacts with indigo in the measuring medium to form isatin (Dräger, 2011; Gastec, 2012; Sensidyne, 2006). Indigo is a blue-colored multi-ringed structure consisting of two identical halves held together by a carbon-carbon double bond. Reaction with ozone splits the molecule into two identical fragments (isatin molecules) that have slightly different structure from each half of the starting material. Isatin is colorless. This reaction, while complex, is not specific to ozone, as indicated in data sheets provided by the manufacturers of these products. Nitrogen dioxide also reacts with indigo to produce isatin.

Dräger indicates that $1 \mathrm{ppm}$ of $\mathrm{NO}_{2}$ does not interfere with the reading of ozone. Higher concentrations change the indicating layer to a diffuse white or gray (Dräger, 2011). Gastec indicates that a 'plus error' occurs when the concentration of $\mathrm{NO}_{2}$ exceeds $1 \mathrm{ppm}$. The entire reagent discolors to white at $6 \mathrm{ppm}$ (Gastec, 2012). The limit of detection of the Dräger product is $0.005 \mathrm{ppm}$ (100 pump strokes) and $0.025 \mathrm{ppm}$ for the Gastec product (10 pump strokes). These levels are suitably low for measuring workplace exposure to ozone. The upper limit of measurement depends on the tube and extends as high as $200 \mathrm{ppm}$. This considerably exceeds the capacity that is required.

\subsection{Proof of Concept Testing}

The second part of this study involved demonstration testing shown in Table 6. Demonstration testing showed that this technology is suitable for determining exposure of welders to ozone in the welding plume and that the products from the two manufacturers, Dräger and Gastec produced almost identical results. This observation confirms previous discussion concerning accuracy of the readings. Either product would be suitable in this application. The Dräger product (\# 6733181 ozone $0.05 \mathrm{~b}$ ) is the more suitable for short-duration sampling because of the shorter duration of the pump stroke and ease of readability. Measurement using short-duration sampling during these activities requires careful attention to ensure that sample collection occurs only during active production of the plume. Detector tubes respond rapidly enough to enable measurement with reasonable expenditure of effort. They suffer possible positive interference from high levels of nitrogen dioxide. At worst, this would lead to overestimation of concentration. Participation and involvement of a human sample-taker who works with the welder are also required.

Determination of exposure to ozone is complicated by the fact that another approach is needed for determination of shift-length exposure for comparison against regulatory Exposure Limits such as the TLV-TWA for ozone. Products designed for long-duration sampling during the workshift using the same technology as in the colorimetric detector tube are also available. Obtaining an estimate of welder exposure by these methods would require integration of the ozone exposure measured during welding with the level of ozone measured during the remainder of the workshift. In another article in this series, McManus and Haddad (2019a) showed that this integration is feasible.

\section{Conclusions}

Selecting a technology for assessing exposure of welders to ozone is a complicated decision. None of the technologies examined here outperformed the others to the extent needed to offer a clear-cut advantage. On the basis of these tests, the technology that appears to offer the fewest weaknesses and limitations for measurement of ozone during welding activities (fitting, tacking and production welding) and assessing exposure is colorimetric detection. Colorimetric detection is available in detector tubes used in samples of short duration as investigated here. The same chemistry is available in badge samplers intended for use during sampling of long 
duration, including full workshifts.

\section{Acknowledgments}

TNM received a scholarship from CAPES (Coordenação de Aperfeiçoamento de Pessoal de Nível Superior), Brasilia, DF, Brasil and CNPq (Conselho Nacional de Desenvolvimento Científico e Tecnológico), formerly Conselho Nacional de Pesquisas, Brasilia, DF, Brasil (the Brazililian National Research Council) in pursuit of this work. Special thanks are due to Jack Eusebio of Fred Thompson Contractors, Burnaby, British Columbia, Canada for permission to work on their premises during this work and to Bob Henderson of GfG Instrumentation Inc. for making available the instruments used during this work.

\section{Conflicts of Interest}

The authors declare no conflict of interest.

\section{References}

ACGIH (American Conference of Governmental Industrial Hygienists). (2001). Ozone. In Documentation of the $T L V S \circledR$ and $B E I S{ }^{\circledR}$. Cincninati, $\mathrm{OH}$ : American Conference of Governmental Industrial Hygienists. [CD-ROM]

ACGIH (American Conference of Governmental Industrial Hygienists). (2018). TLVS ${ }^{\circledR}$ and BEIs ${ }^{\circledR}$ for Chemical Substances and Physical Agents \& Biological Exposure Indices. Cincinnati, $\mathrm{OH}$ : American Conference of Governmental Industrial Hygienists.

Anseros. (2019). Anseros Ozone Gas analyzer LUM. Tübingen, Germany: Anseros Klaus Nonnenmacher GMBH. Retrieved from https://www.anseros.de/ozone/ozone-gas-analyzer-lum/.

ASME (American Society of Mechanical Engineers). (2010). ASME boiler and pressure vessel code. IX Operators. New York, NY: American Society of Mechanical Engineers.

CSA (Canadian Standards Association) Group. (2011). Certification of companies for fusion welding of aluminum (CAN/CSA W47.2-11). CSA Group: Mississauga, ON.

Dräger. (2011). Dräger - Tubes \& CMS - Handbook, $16^{\text {th }}$ ed. Lubeck, Germany: Dräger Safety.

Eco Sensors. (2000). Ozone sensor, Model A-21ZX, instructions for use. Newark, CA: Eco Sensors, Inc.

ENMET. (2002). ENMET: SPECTRUM Series Instrument Manual, MCN-276, 05/06/2002. Ann Arbor, MI: ENMET Corporation.

Gastec. (2012). Gastec Environmental Analysis Technology Handbook (12th ed.). Kanagawa Japan: Gastec Corporation.

Goller, J. W., \& Paik, N. W. (1985). A comparison of iron oxide fume inside and outside of welding helmets. American Industrial Hygiene Association Journal, 46(2), 89-93.

Johnston, A. R., Dyrud, J. F., \& Shih, Y. T. (1989). Ozone removal capability of a welding fume respirator containing activated charcoal. American Industrial Hygiene Association Journal, 50, 451-454.

Lenntech. (2019). Ozone reaction mechanisms. Delft, The Netherlands: Lenntech BV. Retrieved from http://www.lenntech.com/library/ozone/reaction/ozone-reaction-mechanisms.htm\#ixzz2m9SLVzMV.

Lynch, J. R. (1994). Measurement of worker exposure. In R. L Harris, L. J. Cralley., \& L. V. Cralley (Eds.), Patty's Industrial Hygiene and Toxicology (3rd ed., Vol III Part A), Theory and Rationale of Industrial Hygiene Practice. New York: John Wiley \& Sons, Inc.

McKinlay, A. (1992). Optical radiation. In M. W. Greene (Ed.), Non-Ionizing Radiation. Proceedings of the 2nd International Non-Ionizing Radiation Workshop, Vancouver, British Columbia, Canada, 1992 May 10-14. London, England: International Radiation Protection Association, Institution of Nuclear Engineers.

McManus, T. N., \& Haddad, A. N. (2013). UV and blue-light exposures in an aluminum shipbuilding environment. International Journal of Open Scientific Research, 1(6), 15-27.

McManus, T. N., \& Haddad, A. N. (2014). Use of methanol as a coolant during machining of aluminum in a shipbuilding environment: a failure to assess and manage risk. Advanced Materials Research, 955-959, 1061-1064.

McManus, N., \& Haddad, A. N. (2015a). Oxygen levels during welding assessment in an aluminum shipbuilding environment. Professional Safety, 60(7), 26-32. 
McManus, N., \& Haddad, A. N. (2015b). Argon-related fatigue: an investigation in an aluminum shipbuilding environment. Professional Safety, 60(10), 47-55.

McManus, T. N., \& Haddad, A. N. (2016). Chromium emissions during welding in an aluminum shipbuilding environment. Welding Journal, 95(03), 86-s to 92-s.

McManus, T. N., \& Haddad, A. N. (2018). Welder exposure to $\mathrm{NO}$ and $\mathrm{NO}_{2}$ during argon-shielded arc welding on aluminum alloys. Toxicological and Environmental Health Sciences, 10(5), 297-306.

McManus, T. N., \& Haddad, A. N. (2019a). Ozone: a critical contaminant produced during gas metal arc welding (GMAW) on aluminum alloys - resolving the short- versus long-duration sampling discrepancy. Air Quality, Atmosphere and Health, 12(1), 97-106. https://doi.org/10.1007/s11869-018-0634-9

McManus, T. N., \& Haddad, A. N. (2019b). Assessment of technologies for measuring exposure to $\mathrm{NO}_{2}$ during welding on aluminum alloys. Environment and Natural Resources Research, 9(2), 75-85. https://doi.org/10.1007/10.5539/enrr.v9n2p75

Moyer, N. (2019). The evolution of shielding gas. American Welding Society: Miami, FL, 2002. Retrieved from https://app.aws.org/wj/2002/09/feature1/.

NIOSH (National Institute for Occupational Health and Safety). (1988). Criteria for a Recommended Standard, Welding, Brazing, and Thermal Cutting (DHHS (NIOSH) Publication No. 88-110). Cincinnati, OH: Department of Health and Human Services (US), Public Health Service, Centers for Disease Control, National Institute for Occupational Safety and Health.

OSHA (Occupational Safety and Health Administration) (2008). Ozone in workplace atmospheres (Impregnated glass fiber filter), ID-214. Salt Lake City, UT: Department of Labor, Occupational Safety and Health Administration, Salt Lake Technical Center, Branch of Inorganic Methods Development.

Rakness, K., Gordon, G., Langlais, B., Masschelein, W., Matsumoto, N., Richard, Y., Robson, C.M., \& Somiya, I. (1996). Guideline for measurement of ozone concentration in the process gas from an ozone generator. Ozone Science and Engineering, 18, 209-229.

Seinfeld, J. H., \& Pandis, S. N. (1998). Atmospheric Chemistry and Physics - from Air Pollution to Climate Change. New York: John Wiley and Sons.

Sensidyne. (2006). Sensidyne Colorimetric Gas Detector Tubes Handbook. St Petersburg, FL: Sensidyne Corporation.

Swint W. (2015). Parameters employed during welding on aluminum during construction of the PacifiCats. Victoria, BC, Canada: March 11, 2015. [personal communication].

TAPI. (2016). Model T265 Chemiluminescence Ozone Analyzer. San Diego, CA: Teledyne Advanced Pollution Instrumentation.

TECO. (1994). Model 49 Series Instruction Manual. Franklin, MA: Thermo Environmental Instruments Inc.

Thermo Electron. (2004). Model 42C, chemiluminescence $\mathrm{NO}-\mathrm{NO}_{2}-\mathrm{NO}_{x}$ analyzer. Franklin, MA: Thermo Electron Corporation.

WorkSafeBC. Occupational Health \& Safety Regulation, Part 5, Chemical agents and biological agents (BC Regulation 296/97, as amended). (2019). Richmond, BC: Workers' Compensation Board of British Columbia. Retrieved from http://www2.worksafebc.com/publications/OHSRegulation/Introduction.asp\# AboutOccupationalHealthSafetyRegulation.

\section{Copyrights}

Copyright for this article is retained by the author(s), with first publication rights granted to the journal.

This is an open-access article distributed under the terms and conditions of the Creative Commons Attribution license (http://creativecommons.org/licenses/by/4.0/). 